\title{
UNA MANERA GEMELA DE SENTIR: EUCLIDES DA CUNHA Y GAYO C. TACITO
}

\author{
Bartolomé Segura Ramos
}

A fines del siglo pasado, un pueblecito del Nordeste de Brasil, Canudos, acaparó la atención pública del país y motivó la intervención del Estado. Formado por míseras chozas, en esa «Troya de barro» hallaron acogida todos los miserables de la región bahiana. Allá acudieron mujeres de toda condición, viejos y enfermos, bandidos y cangaçeiros, y unidos en torno a un fanático, Antonio Conselheiro, concibieron la idea de vivir al margen del tiempo y de la historia en una comunidad cristiana en la que se mezclaban ideas ortodoxas de la Iglesia católica con aberraciones irreconciliables y prácticas ascéticas que la misma Iglesia reputaba de excesivamente rigurosas. Aunados en el bien y en el mal, entregados por igual a rezos cotidianos y dolorosas procesiones y a saqueos y pillajes, pronto atrajeron la atención de las autoridades, tanto religiosas como políticas y militares.

En los últimos días del año 1896 se envió una expedición militar compuesta por poco más de cien hombres, que fue fácilmente derrotada por el pueblo de iluminados. A ella siguió una segunda expedición en los primeros meses de 1897, compuesta por 543 hombres y varios cañones Krupp que fue igualmente desbaratada por los rebeldes. Todavía, antes de la destrucción final, Canudos hubo de soportar el envío de un contingente mayor (1.300 hombres) al mando del famoso coronel Moreira César, que contra todo pronóstico, resultó asimismo diezmado, muriendo también el comandante de la fuerza. Por último, consciente el gobierno de la República de que Canudos no era simplemente una «caverna de bandidos» o de fanáticos enloquecidos, se aprestó para la batalla final, organizando una cuarta expedición en la que llegaron a participar a lo largo de la campaña cerca de diez mil hombres con tres generales al frente, la cual luego de largos meses de asedio y de privaciones, y tras sufrir incontables pérdidas, logró la destrucción completa de Canudos en el mes de octubre de ese año. 
La historia de Canudos ha sido descrita pormenorizadamente por el escritor brasileño Euclides da Cunha (Río de Janeiro, 1866-1909), quien como corresponsal del diario Estado de Sâo Paulo estuvo presente en la última y definitiva campaña. No obstante, por informaciones orales y de la prensa, da Cunha revela un conocimiento de las tres primeras expediciones tan completo como el de la última, en la que él participó.

La obra en que describe esta singular historia lleva por título Los Sertones (1902), que no es apropiado clasificar como novela. En realidad, se trata de una obra heterogénea, en la que se mezcla el concepto de libro de historia, de texto de geografía y de etnografía, cuando menos. De las 485 páginas que abarca el libro en la traducción española, menos de doscientas las dedica el autor a describir la tierra y el hombre*, y las trescientas restantes a narrar la historia de la campaña de Canudos. En general, se conviene en que se trata de una obra singular, cuyo tono épico salta a la vista, y por lo demás se la considera fundadora de la literatura brasileña, así como la Biblia de la nacionalidad de este país.

$\mathrm{Da}$ Cunha perfila una historia del Brasil desde sus fundadores portugueses hasta el momento del conflicto de Canudos; describe la mezcla de razas, que según general sentir se ha realizado en Brasil con una permeabilidad generosa y modélica (así es como Gilberto Freire contrapone dicha permisibilidad a las trabas que padeció - y padece - Estados Unidos entre los Estados del Sur y los Estados del Norte), y se muestra orgulloso al describir el carácter de los diferentes tipos humanos que se han amalgamado en el gran país. Hay en toda la obra una comunión entre la naturaleza y el hombre que hace a ambos inseparables, y por ello insistirá tanto el autor en la descripción pormenorizada de los paisajes, los montes, los ríos, los sertoes y las caatingas.

El poder evocador y descriptivo de este autor brasileño es extraordinario. La pasión, el vigor, la fuerza, la sensibilidad y lucidez que recorren la obra están fuera de lo común. Llama la atención la intensidad poética de su narración, la riqueza verbal y las descripciones majestuosas de las fuerzas naturales y las fuerzas humanas desatadas como si de un aluvión o un huracán se tratase.

Antes de seguir adelante, tal vez convenga señalar que la historia de Canudos ha sido la base de partida, o, más bien, motivo de reelaboración y conversión en novela pura por el escritor peruano Vargas Llosa, que la ha transformado en la conocida novela «La guerra del fin del mundo». Este escritor ha tomado literalmente la historia que narra Euclides da Cunha, que en lo estrictamente militar y bélico, en los personajes (desde António Conselheiro hasta el León de Natuba, pasando por Pajeú, Juan Abad, Pedrâo, el Esclavo, etc.), los avatares y detalles ínfimos, es seguida al pie de la letra por el novelista. Este ha adornado la historia con desarrollos imaginarios que, no obstante,

* Como ingeniero que era, Da Cunha se extiende en el análisis de la estructura y morfología geológica de las tierras descritas. En este proceder tiene entre nosotros un sucesor distinguido: $\mathrm{El}$ escritor Juan Benet. Recuérdense las primeras páginas de Volverás a Región. 
tienen su fundamento igualmente en la obra de Da Cunha: Galileo Gall y su obsesión por descubrir la psicología de los hombres mediante los rasgos faciales y la configuración craneana nacen de algunas sugerencias del brasileño en este sentido; la figura del fazendeiro halla justificación en alusiones perfectamente localizables en Los Sertones, y la intimidad de la vida en Canudos ha debido ser imaginada por el novelista a partir de los datos suministrados por Da Cunha, que conoció los detalles de la vida de ese miserable y desgraciado pueblo por haber sido testigo ocular durante meses de la vida que allí se desarrollaba. Y, curiosamente, hay que dejar constancia de que pese al arte moderno y sui generis con que Vargas Llosa narra su novela (que, sin embargo, quizá por influencia de su modelo, no distorsiona el tiempo tanto como en sus otras novelas, y el lenguaje, a diferencia de éstas, es aquí de una brillantez ampulosa y rica, que lo emparenta con García Márquez), no consigue, a mi juicio, superar la técnica más lineal del escritor brasileño: la fuerza poética y emotiva de éste es difícilmente superable, el dramatismo, la angustia y la incertidumbre se revelan más palmariamente, más impresivamente, en la narración de Euclides que en la del peruano. Sorprende, por otra parte, que Vargas Llosa no haya dejado constancia en la publicación de su novela de esa mímesis que perpetra en la obra de Da Cunha. No creo que sea ilegítimo recrear ficticiamente una realidad histórica narrada por quien tan bien conoció dicha realidad, y no hay razón ninguna para ocultar este proceder.

Pero por lo que a mí hace ha sido una nítida sensación de clasicidad en el sentido tradicional del término la que me ha hecho esta obra del brasileño doblemente atractiva. Por una parte, esas cualidades, enumeradas anteriormente, que todo el mundo reconoce y que se apoderan del lector desde el primer momento. Por otra, es que su dramatismo y emotividad, su garra, la especial manera, inusitada en lo que conozco de historia y de historia de la literatura, de narrar, emparenta a Euclides da Cunha nada menos que con los clásicos latinos, y en especial, como veremos más abajo, con el historiador romano Gayo Cornelio Tácito.

En efecto, es en este contexto de dramatismo, poesía, evocación emotiva, así como también en el análisis de los comportamientos sociales y bélicos, la crítica (moral) y el interés y profundidad psicológicos, donde el parangón con Tácito cobra tan gran relieve que uno se siente tentado a afirmar que el gran brasileño había conocido y bebido en el gran romano. No es fácil hallar otro caso en que la historia bélica, la psicología social e individual, la descripción de las fuerzas naturales y el desarrollo de los eventos, entreverados inextricablemente, hallen un tratamiento tan taciteano, tan sostenido y elevado, y ello teniendo en cuenta además que la fuerza dramática y narrativa de Tácito es un hecho singular en la literatura latina. De ahí la feliz, increíble, maravillosa coincidencia. De ahí, la admiración, la sorpresa, la fascinación.

A continuación voy a intentar ilustrar someramente esta insospechada coincidencia. 
Primeramente, es fácil comprobar que Euclides da Cunha, que era ingeniero, militar y periodista, poseía una amplia cultura, histórica y literaria, que se deja ver en su obra. Nombres como Bossuet, Taine, Hegel, Buckle, Bates, Klopstock, Brunswick, Maudsley y otros, a los que se refiere oportunamente a lo largo de sus páginas, lo corroboran. También es fácil percatarse de su conocimiento de historia militar. Así, en la página 199 (de la traducción española, editada por la Editorial Fundamentos, 1981; todas las referencias a páginas lo serán a esta edición; lamentablemente, la traducción es pésima) dice que «Canudos era nuestra Vendée», y en la página 284, que «Canudos era una Coblentz de viviendas en ruinas». Pero es de la cultura clásica y más específicamente de la latina con la que demuestra una notable familiaridad. Rastreando, podemos citar: en pág. 94 afirma que el sertanero es «Hércules-Cuasimodo». En pág. 124, dice: «Bastaría que volviésemos a los primeros días de la Iglesia, cuando el gnosticismo universal se erigía como obligatoria transición entre el paganismo y el cristianismo, en la última fase del mundo romano en que, precediendo la invasión de los bárbaros, la literatura latina del occidente declinó, de súbito, apenas sustituida por los míseros sofistas y letrados de Bizancio». Y continúa en la página siguiente: «Amoldáronse bien (las diversas sectas citadas anteriormente: montanistas, adamitas, ofiólatras, maniqueos, discípulos de Marcos, encratistas) a todas las tendencias de la época en que las extravagancias de Alejandro Abnótico agitaban la Roma de Marco Aurelio, con sus procesiones fantásticas, sus misterios y sus sacrificios tremendos de leones arrojados vivos al Danubio, en medio de solemnidades imponentes, presididas por el emperador-filósofo». En pág. 149 llama a Canudos una «Troya de barro»; en 151, hablando de las casas de ese pueblo, dice: «Recordaban las chozas de los galos de César». Al pie de la página 156 hay una cita del Marc-Aurèle, de Rénan, donde éste habla de Montano, que Euclides ha nombrado ya en dos ocasiones: pp. 140 y 142. En 157 habla de los germanos; en 198, del Minotauro y también de Anteo indomable. En 291-292, apunta: «Las gentes alucinadas oían un tropel de bárbaros... Los batallones de Moreira César eran las legiones de Varo...». En 322: «Los elefantes de Pirrro». En 351 (hablando del general Artur Oscar, comandante en jefe de la cuarta y última expedición): «Alteró un verbo en la frase clásica del romano y siguió. Llegó, vio y se quedó». En 363 alude a las «horcas caudinas».

Por otra parte, podemos recoger un repertorio curioso de frases o palabras latinas que salpican las páginas de Los Sertones: 63 (y 240), diuortium aquarum; 74, ultra aequinoctialem non peccaui; 93, norma uerticalis; 115, in partibus; 146, uia sacra; 150, «definía bien la ciuitas siniestra del error»; 155, «régimen de la urbs»; 161, «el arx monstruoso»; 165 y 189: los kyries (palabra griega, no latina); 166, mea culpa; 173, Prima Petri; 175, «al ueredictum de la Justicia Divina»; 207, «la uis a tergo»; 214, sine calcei linimentis; 222, legio fulminata; 290, Pro Pace.

Creo que este recorrido de citas revela el contacto y conocimiento que Da Cunha tenía de la historia romana. Fijémonos en las legiones de Varo, cuya suerte relata Tácito en sus Anales, en la legio fulminata, una de las treinta legiones que tenía el Imperio Romano en la época del escritor latino. 
Ahora voy a intentar mostrar cómo el estilo del autor brasileño ofrece numerosos puntos de contacto con el historiador romano. Empecemos con las etopeyas. En ambos autores son frecuentes. Elijamos algunos casos al azar.

Personajes de Euclides da Cunha.

Los Sertones, pp. 232-234, el coronel Moreira César: «El aspecto reducíale la fama. De figura diminuta - un tórax desfibrado sobre piernas arqueadas en paréntesis - era, orgánicamente, inapto para la carrera que abrazara. Le faltaba el aplomo y la complexión enteriza que en el soldado son la base física de la intrepidez. Ceñido en el uniforme que raramente dejada de usar, el dolman hecho para hombros de adolescente, le agradaba la apostura. Su fisonomía inexpresiva y mórbida, completaba el porte desgarbado y exiguo. Nada, absolutamente nada, denunciaba en aquel rostro de convaleciente, la energía admirable y la temeridad extraordinaria de que diera pruebas: sin una línea original y firme, pálido, alargado por la calva en que se expandía la frente bombeada, iluminado apenas por una mirada mortecina, velada por una permanente tristeza. Era un rostro inmóvil, como modelado en cera, que tenía la impenetrabilidad oriunda de la propia atonía muscular. Los grandes paroxismos de la cólera y la alegría más intensa debían desmayar allí inadvertidos, en la laxitud de los tejidos, dejándola siempre fijamente impasible y rígida.

A quienes le veían por primera vez les costaba admitir que hubiese en aquel hombre de gesto lento y frío, de maneras corteses y un tanto tímidas, el campeador brillante o el demonio sanguinario que idealizaban. No tenía los trazos característicos ni de uno ni de otro. Acaso porque fuese ambas cosas al mismo tiempo /.../».

Los Sertones, p. 301, el teniente coronel Sequeira de Meneses: «Nadie hasta entonces había comprendido con igual lucidez la naturaleza de la campaña, o estaba mejor aparejado para ello. Firme educación teórica y espíritu observador, lo tornaban guía exclusivo de aquellos millares de hombres tactivos en región desconocida y bárbara. La había recorrido casi solo, acompañado de uno o dos ayudantes, en todo sentido. La conocía por completo, e infatigable, ajeno a todo temor, aquel campeador que se había formado fuera de la vida de los cuarteles, sorprendía a los combatientes más surtidos. Se echaba por las chapadas amplias, se perdía en los desiertos repletos de emboscadas, observando, estudiando, y, muchas veces, luchando. Cabalgando animales estropeados, inaptos para un medio galope, se perdía entre las quebradas, trasponiéndolas; escalaba los cerros más abruptos, en reconocimientos peligrosos, y aparecía en Caypan, en Calumbi y en Cambaio, en todas partes, más preocupado de su cartera de notas y croquis rápidos que de su vida».

Los Sertones, p. 323, el coronel Carlos Teles: «Perfecto especimen de esos lidiadores riograndenses - un jefe y un soldado - osado y reflexivo, impávido y prudente, mezcla de acometidas temerarias y de bravura serena, no desdeñando pelear al lado del soldado de enganche en lo más encarnizado de los encuentros, pero después de haber planeado fríamente la maniobra». 
Los Sertones, pp. 400-401, el mariscal Bittencourt: «Era un hombre frío, tocado de un escepticismo tranquilo e inofensivo. En su sencillez perfectamente plebeya se amortiguaban todas las expansiones generosas. Militar a derechas sería capaz - y lo demostró más tarde ultimando trágicamente su vida - de arrojarse a los mayores peligros. Pero fríamente, equilibradamente, encarrilado en las líneas inextensibles del deber. No era un bravo y no era un pusilánime /.../».

Personajes de Tácito.

Historias, I 10, el general Muciano: «Siria y cuatro legiones las mandaba Liciano Muciano, individuo de renombre tanto por sus éxitos como por sus desgracias. De joven había cultivado con empeño amistades ilustres. Después, dilapidada su fortuna, en situación insegura, sospechando de él además el airado Claudio, fue apartado en un rincón de Asia, donde estuvo tan cerca de ser un exiliado como más tarde de ser emperador. Era una mezcla de derroche y de laboriosidad, de amabilidad y de arrogancia, de cualidades buenas y malas. Cuando no tenía nada que hacer sus placeres eran desmesurados; cuando iba de campaña, sus cualidades militares eran grandes; se podían alabar sus actos públicos, pero sus acciones privadas tenían mala fama. Mas era poderoso entre sus subordinados, sus allegados, sus compañeros, porque recurría a señuelos diversos; en fin, era un hombre al que resultaba más cómodo entregar el Imperior que poseerlo».

Historias, I 48, el general Tito Vinio: «Tito Vinio vivió cincuenta y siete años y su moral fue cambiante. Su padre era de familia pretoria, su abuelo materno había estado proscrito. Durante los primeros años de servicio tuvo mala fama. Su lugarteniente fue Calvisio Sabino, cuya mujer tuvo el perverso deseo de visitar el emplazamiento del campamento y penetró en él de noche vestida con uniforme militar; merodeó por los puestos de centinelas y otras ocupaciones militares con idéntico desatino y en el mismo cuartel general tuvo la osadía de cometer estupro, y fue Tito Vinio el acusado de este hecho. De modo que por orden de Calígula fue cargado de cadenas, y, luego, al cambiar los tiempos, quedó libre e hizo una carrera política sin mácula. Después de la pretura obtuvo el mando de una legión con buena hoja de servicios, aunque acto seguido se manchó con un acto propio de esclavos, robando, al parecer, una copa en un banquete de Claudio, y éste al día siguiente ordenó que sirvieran en copas de barro únicamente a Tito Vinio. Ahora bien, Vinio gobernó como procónsul la Galia Narbonense con severidad e integridad; más tarde, por su amistad con Galba, fue arrastrado al precipicio, audaz, astuto y decidido como era, con idéntica energía malvado o solícito, a tenor con los impulsos de su espíritu».

Historias, I 53, el general Cecina: «En la Germania Superior Cecina, en espléndida juventud, físicamente corpulento, de espíritu desenfrenado, de hábil diálogo y andares estirados, se había granjeado los ánimos de los soldados».

Historias, II 50, el emperador Otón: «Su origen era el municipio de Ferentio, su padre fue cónsul, su abuelo, pretor. La línea materna no rayaba tan alto, 
pero tampoco desmerecía. Su niñez y juventud, como hemos referido. Por dos actuaciones, una vergonzante, la otra, eximia, mereció ante la posteridad tanta fama buena como mala».

En Tácito, como todo conocedor de este historiador sabe desde el primer momento, abundan las reflexiones morales. Tampoco faltan en Euclides da Cunha.

Un ejemplo, Los Sertones, p. 257: «Porque en un ejército que persigue hay el mismo automatismo impulsivo de los ejércitos que huyen. El pánico y la bravura enajenadas, el extremo pavor y la audacia extrema se confunden en el mismo aspecto. El mismo aturdimiento, el mismo ímpetu precipitado entre los mayores obstáculos, el mismo vértigo, la misma neurosis torturante sacudiendo las filas y la misma ansiedad dolorosa, estimulan y alucinan con idéntico vigor (cf. supra, el retrato de Tito Vinio: con idéntica energía, eadem ui).

Un ejemplo de Tácito: Historias, I 1: «Muchos historiadores han narrado los ochocientos veinte años transcurridos desde la fundación de Roma, y mientras eran gestas del pueblo romano se contaban con igual elocuencia que libertad. Después de la batalla de Actio y cuando fue necesario para la paz entregar todo el poder a uno solo, aquellos grandes talentos desaparecieron. Al mismo tiempo la verdad fue conculcada de mil maneras, lo primero por el desconocimiento que se tenía de la república, que era una extraña, luego, por el gesto de adular o, al contrario, por odio a los que mandaban. De modo que nadie se preocupaba de la posteridad, pues o se mostraban todos enemigos o estaban sometidos. Pero es que son fáciles de evitar las pretensiones de un historiador, en tanto que la calumnia y la envidia se oyen con oídos atentos por la sencilla razón de que la adulación acarrea el feo reproche de servidumbre, y en cambio en la maledicencia hay una falsa apariencia de libertad».

Muchos son los pasajes en que se describe la naturaleza y sus fuerzas desatadas. Elegimos un ejemplo.

Los Sertones, pp. 194-196: «Las caatingas son un aliado incorruptible del sertanero en rebelión. Entran también de cierta manera en la lucha. Se arman para el combate; agreden. Se enmarañan, impenetrables, ante el forastero; pero se abren en múltiples senderos para el lugareño que allí nació y creció. /.../ Las caatingas no lo ocultan tan solamente, sino que lo amparan. Al divisarlas en el verano una columna en marcha no se sorprende. Sigue por los caminos en meandros, libremente. /.../ De repente, en uno de los flancos estalla próximo un tiro... La bala pasa silbando, o extiende sin vida en tierra a un hombre. Se suceden, pausadas, otras, pasando sobre las tropas, en silbidos prolongados. Cien, doscientos, mil ojos escrutadores se vuelven impacientes en derredor. Nada ven. Se produce la sorpresa. Una onda de espanto recorre de un extremo a otro las filas. Y los disparos continúan raros, pero insistentes y acompañados por la izquierda, por la derecha, por el frente ahora, brotando de todas partes... Y una extraña sensación invade a los más probados valientes, ante el antagonismo que ve y no es visto. Se forma rápidamente con tiradores una compañía apenas destacada de la masa de batallones oprimidos en la vereda 
estrecha. Se extiende por el borde de la caatinga. Se oye una voz de mando, y un torbellino de balas rueda atronadoramente dentro de los ramajes...»**

Tácito, Anales, II 23: «Al principio, el mar calmado resonaba con el estrépito de los remos de mil naves o se dejaba surcar a vela. Luego, se desató una granizada en medio de una montaña de nubes negras, al tiempo que olas imprevisibles, removidas por galernas que acosaban de todas partes, quitaban la visión, impedían el pilotaje. Los soldados, asustados, inexpertos en los avatares del mar, entorpecían la labor de los entendidos, perturbando la marinería o ayudándola intempestivamente. A partir de ahí todo el cielo y el mar todo cedieron al austro que, recio por las tierras quebradas de Germania, en los ríos profundos, por las inmensas masas de nubes, y más espeluznante por el rigor del vecino Septentrión, arrastró y dispersó las naves por el Océano abierto, o hacia islas peligrosas por sus roquedales abruptos o sus bajíos invisibles. Una vez que a duras penas evitaban estas islas, cuando cambiaba la marea y los llevaba en la misma dirección que el viento, no podían fijar anclas, no podían achicar las olas que irrumpían. Arrojaban por la borda los caballos, los mulos, los equipajes, incluso las armas, para aligerar las bodegas de los barcos que hacían agua por los flancos y eran aplastados por las olas».

En incontables ocasiones tanto uno como otro autor describen concienzudamente la disposición de las tropas a la hora de entrar en combate. En ambos hay un mismo gusto por el registro minucioso de los hombres que combaten destacados sobre el terreno en el instante mismo de la pelea.

Los Sertones, pp. 329-330: «La quinta brigada, que desde el principio se mantenía en sus posiciones entre las caatingas, debía cargar por el flanco izquierdo y por el lecho del río, a fin de desalojar al enemigo de los cerros centrales y colinas que quedan de ese lado; y la cuarta por el flanco derecho, debiendo, antes, desplegarse en línea, al salir del camino hacia el llano. El escuadrón de lanceros, entre ambas, atacaría por el centro. La sexta brigada no participaría en el combate, permaneciendo a retaguardia como refuerzo, afianzando los convoyes. De esta manera los cinco batallones destinados al ataque se disponían en orden perpendicular, reforzados en una de sus alas, y de la izquierda, donde los cuerpos avanzados del coronel Serra Martíns formaban en columnas sucesivas mientras cuatrocientos metros atrás y hacia la derecha, se desdoblaba en línea la brigada Teles, teniendo en el flanco izquierdo el escuadrón de lanceros».

Tácito, Historias, II 24: «Colocan a la izquierda una bandera de la legión decimotercera, cuatro batallones de tropas auxiliares y quinientos jinetes. Tres batallones pretorianos ocuparon en filas profundas el talud de la carretera. Por el flanco derecho avanzó la primera legión con dos batallones de tropas auxiliares y quinientos jinetes. A más de éstos, alinearon mil jinetes de la guardia imperial y de la fuerza auxiliar, que serían el broche de oro si las cosas iban bien, o, si no, un auxilio en caso de ir perdiendo».

* Merece la pena recordar aquí a Joseph Conrad y su novela El corazón de las tinieblas, donde este precursor de Kafka describe un parecido terror invisible. 
Tácito, Historias, III 21: «Ordena tomar posiciones a la legión decimotercera en el mismo talud de la vía Postumia; a renglón seguido, a la izquierda, se estableció la séptima galbiana en el llano abierto, a continuación, la séptima claudiana, pertrechada con una trinchera rústica, pues así era el lugar; a la derecha, se colocó la octava en un sendero abierto, y luego la tercera, protegida por densos arbustos. Este era el orden de las águilas y las enseñas. Los soldados se entremezclaron en las tinieblas, como quiso el azar; la bandera de la guardia pretoriana estaba en las inmediaciones de los legionarios de la tercera, los batallones de la fuerza auxiliar en las alas, y los flancos y la retaguardia quedaron envueltos por la caballería».

Es curioso constatar la similitud en los procedimientos de intimidación del enemigo por medio de cánticos. En el caso del autor brasileño son los fanáticos quienes ponían nerviosos a los soldados con sus rezos; también a los romanos incomodaban las canciones de los germanos.

Los Sertones, p. 275: «Allá por medianoche todas las aprehensiones se agrandaron. Los centinelas que cabeceaban en las filas débiles del cuadro, se estremecieron, súbitamente despertados, conteniendo gritos de alarma. Un rumor indefinible avasalló la mudez ambiente y subía por las cuestas. No era, empero, un sordo tropel de asalto. Era peor. El enemigo, abajo, en el poblado invisible, rezaba. Y aquella serenidad extraordinaria, letanías tristes, en que predominaban en vez de gritos varoniles voces de mujeres, surgiendo de las ruinas de un campo de combate, era, a aquella hora, formidable. Actuaba por el contraste. Por el murmullo de la soldadesca pasmosa, los kyries estropeados y dolientes, entraban peores que intimaciones enérgicas. Decían, de una manera elocuente, que no había forma de resistir contra adversarios de tal forma transfigurados por la fe religiosa».

Tácito, Anales, I 65: «La noche transcurría intranquila por causas opuestas: los bárbaros abrumaban los fondos de los valles y los sotos, que repetían el eco, con sus banquetes festivos, su alegre canto o su atroz escándalo; entre los romanos los fuegos languidecían, las conversaciones se habían interrumpido, y ellos andaban echados por todas partes junto a la empalizada, o vagaban delante de las tiendas, desvelados más que velando».

Tanto Tácito como Euclides da Cunha se recrean en la descripción del escenario de los combates. El aspecto que ofrecen dichos escenarios después de la batalla los impresiona a ambos por igual, y su descripción nos impresiona a nosotros.

Los Sertones, pp. 280-281: «Terminadas las búsquedas en los alrededores y recogidas las armas y municiones de guerra, los yagunzos recogieron los cadáveres que yacían esparcidos en diversos puntos. Los decapitaron. Quemaron sus cuerpos. Alinearon después, en los dos bordes del camino, las cabezas, regularmente espaciadas, enfrentándolas con los rostros vueltos hacia el camino. Por encima, en los arbustos marginales más altos, colgaron los restos de los uniformes encontrados: pantalones y dólmanes multicolores, monturas, cinturones, kepíes de galones rojos, capotes, mantas, cantimploras y mochilas... La caatinga 
desmirriada y desnuda, apareció repentinamente reventando en una florescencia extravagantemente colorida en el garancé de los distintivos, en el azul desmayado de los dólmanes y en el brillo vivo de las chapas de los tahalíes y estribos oscilantes... Un pormenor doloroso completó esta mise-en scène cruel: a un lado abultaba, empalado, erguido en un gajo seco de curapaí, el cuerpo del coronel Tamarindo. Era asombroso. Como un maniquí terriblemente lúgubre, el cadáver desplomado, brazos y piernas colgantes, oscilando al placer del viento en el gajo flexible y curvado, aparecía en los yermos hecho una visión demoníaca. Allí permaneció largo tiempo...».

Los Sertones, p. 311: «Asomaban por todas partes crueles recordaciones: pedazos descoloridos de uniformes, que oscilaban en los extremos de los gajos secos; viejas monturas y mantas destrozadas, y jirones de capotes esparcidos por el suelo, mezclados a restos de esqueletos. En la margen izquierda del camino, alzado en un tronco - hecho una percha en que estuviera colgado un viejo uniforme - el esqueleto del coronel Nunes Tamarindo, decapitado, con los brazos pendientes, las manos desmirriadas calzando guantes negros... A sus pies yacían el cráneo y las botas. Y pasando del borde del camino hacia el interior de las malezas, otros compañeros de infortunio, esqueletos vestidos de uniforme, polvorientos y rotos, tirados en el suelo, boca arriba, en línea de formación trágica, o desequilibradamente arrimados a los arbustos flexibles que, oscilando al placer de los vientos, les imprimían singulares movimientos de espectros, delataban una endemoniada mise-en-scène adredemente preparada por los yagunzos».

Tácito, Anales, I 61: «Así que al César le entró el deseo de cumplir con los deberes últimos para los soldados y su jefe, en medio de la emoción general del ejército presente motivada por los parientes, amigos, y, en fin, por los azares de las guerras y el destino de los hombres. Se envió delante a Cecina a examinar las entrañas de los desfiladeros y a disponer puentes y diques sobre los húmedos cenagales y las llanuras traicioneras, y entonces penetran en los tristes lugares, desfigurados por lo que se veía y por lo que se recordaba. El primer campamento de Varo con su amplio perímetro y su real inmenso mostraba el esfuerzo de las tres legiones. Luego, cabía entender por la empalizada semiderruida y el foso a flor de tierra que allí se habían instalado los restos ya pulverizados. En medio del llano, huesos blanquecinos, desperdigados o amontonados, según se hubiese huido o se hubiese resistido. Al lado yacían pedazos de lanzas y extremidades de caballos, y había también cabezas clavadas en los troncos de los árboles. En los bosquecillos cercanos se levantaban altares bárbaros en los que habían sacrificado a los tribunos y a los centuriones de primer rango. Y los sobrevivientes de esta carnicería, que se habían escurrido del combate o de las ataduras, referían que aquí habían caído los comandantes, allí les habían quitado las águilas; aquí le habían inferido la primera herida a Varo, allí había encontrado la muerte por su propia mano y su propio impulso, el desgraciado... Señalaban la tarima desde donde Arminio había dado una arenga, los numerosos patíbulos y hoyos, preparados para los prisioneros, y cómo se había mofado Arminio soberbiamente de las enseñas y las águilas». 
Tácito, Historias, II 70: «Desde allí Vitelio torció hacia Cremona, y después de asistir al espectáculo de Cecina le entraron ganas de patear las llanuras de Bedríaco y ver con sus propios ojos las huellas de la reciente victoria, un espectáculo horrible, atroz. A cuarenta días de la batalla los cuerpos estaban dilacerados, los miembros mutilados, podridos hombres y caballos, infectada de podredumbre la tierra; había una cruel devastación de árboles desgarrados y de mieses. Y no menos inhumana era la parte de la vía que los cremonenses habían cubierto de laurel y rosas, con altares levantados y víctimas sacrificadas como se hace con los reyes. Estos gestos que momentáneamente fueron satisfactorios les causaron posteriormente la perdición. Al lado de Vitelio estaban Valente y Cecina y le indicaban los puntos del combate: de aquí habían irrumpido las columnas de las legiones, de aquí se habían lanzado los jinetes, por allí se habían desplegado los contingentes auxiliares. Además, los tribunos y prefectos, exaltando cada cual sus acciones, mezclaban la verdad con la mentira o exageraban sus relatos. También la gran masa de soldados rasos se desvió del camino con gritos y expresiones de júbilo, reconocían su puesto de combate y contemplaban admirados el apilamiento de armas y los montones de cadáveres. Había a quienes se les venía al pensamiento el cambiante destino de las cosas, y les brotaban las lágrimas y sentían compasión. Pero Vitelio no desvió sus ojos ni se espantó ante tantos miles de compatriotas insepultos. Es más, contento e ignorante de su suerte tan cercana instauraba un sacrificio a los dioses del lugar».

Los ejemplos podrían multiplicarse, pero basta con lo apuntado. Porque así me ha parecido a mí: el pulso y la sensibilidad de Tácito han reencarnado en Euclides da Cunha. Quienes conocen la literatura latina saben que la prosa de Tácito es excepcional y no sólo por su originalidad en el manejo de la lengua. También por su lucidez y dramatismo. Por encima de diferencias locales y temporales, sin respeto a la distancia, a través del tiempo impenetrable, ambos autores, el romano y el brasileño, sintieron la naturaleza y la sociedad de la misma forma y las racionalizaron de modo similar. Bien se puede decir de los dos que fueron, que son, «la mitad del alma» el uno del otro. 
